\title{
ANALISA JARINGAN LOKAL AREA NETWORK (LAN) DI SALAH SATU HOTEL WILAYAH JAKARTA TIMUR
}

\author{
Nurwijayanti KN \\ Dosen Universitas Dirgantara Marsekal Suryadarma \\ Jalan Protokol Halim Perdana Kusuma Jakarta Timur \\ Sur-el :nurwijayanti_kn@yahoo.com
}

\begin{abstract}
The development of information technology is increasing every year, one of the applications of information technology is the Loal Area Network (LAN), which is applied in a hotel located in the East Jakarta area, the hotel has 10 floors, consisting of the 1st floor as a server and computer clients are located on floors 2-10. Due to the large number of complaints from guests, especially Wi-Fi network problems, it is necessary to check the maintenance section to see the quality of the network on each floor and an analysis is needed, where the analysis uses the method of calculating QoS (Quality Of Service) using 3 parameters, namely: Delay, Throughput and Packet Loss, with the standards used according to the TIPHON standard to determine the level of computer network quality. The results of the analysis at the hotel can be said to be very good, Delay is said to be very good, Throughput is said to be Good and Packet Loss is said to be Good, then the QoS results on Monday - Sunday obtained an index of 3 which is categorized as Satisfactory, then after analyzing the problem, only bandwidth problems must be enlarged so that the delay is getting smaller.
\end{abstract}

Keywords: QoS, Delay, Throughput, Hotel and Packet Loss

\begin{abstract}
Abstrak: Perkembangan teknologi informasi semakinmeningkat tiap tahunnya, salah satu aplikasi teknologi informasi adalah jaringan Lokal Area Network (LAN), yang diaplikasikan di salah satu hotel yang terletak di wilayah Jakarta Timur, hotel tersebut memiliki 10 lantai, yang terdiri dari lantai 1 sebagai server dan komputer client terletak di lantai 2-10. Karena banyaknya komplain dari para tamu terutama masalah jaringan Wi-Fi, maka perlu adanya pengecekan dibagian maintenance untuk melihat kualitas jaringan ditiap lantai dan perlu dilakukan analisa, dimana analisanya menggunakan metode menghitung QoS (Quality Of Service) menggunakan 3 parameter yaitu : Delay, Throughput dan Packet Loss, dengan standar yang dipakai sesuai standar TIPHON untuk menentukan tingkat kualitas jaringan komputer. Hasil analisa di hotel tersebut di dapat Delay dikatakan sangat bagus, Throughput dikatakan Bagus dan Packet Loss dikatakan Bagus, maka di dapat hasil QoS pada hari Senin - Minggu didapat indeks sebesar 3 dikatagorikan Memuaskan, maka setelah di analisa permasalahannya hanya masalah bandwidth yang harus diperbesar agar delay semakin kecil.
\end{abstract}

Kata Kunci: QoS, Delay, Throughput, Hotel dan Packet Loss

\section{PENDAHULUAN}

Perkembangan teknologi informasi semakin meningkat tiap tahunnya, salah satu aplikasi teknologi informasi adalah jaringan Lokal Area Network (LAN), selain jaringan LAN ada juga jaringan (Wide Area Network) WAN dan (Metropolitan Area Network) MAN. Tapi biasanya jika aplikasinya hanya untuk satu gedung saja cukup menggunakan jaringan LAN.

Hotel adalah salah satu tempat yang nyaman apabila kita berpergian jauh, sebagai sarana tempat istirahat sementara, hotel dibuat oleh pengelola senyaman mungkin agar para tamunya merasa nyaman dan betah berada di hotel tersebut. Fasilitas yang dimiliki seperti kolam renang, fitness center, restoran yang luas 
dan bersih, air panas di tiap kamar hotel, selain kebersihan juga harus diperhatikan sarana lainnya, seperti fasilitas internetnya.

Salah satu yang membuat para tamu akan merasa betah apabila sebuah hotel memiliki koneksi internetnya sangat cepat, baik pada saat mengirim dan menerima email, mendownload dan mengupload data/gambar dan lain-lain. Terkadang koneksi internet di dalam hotel masih terhambat oleh kecepatan dalam memproses data, maka harus diperhatikan jaringan yang ada, jaringan di dalam hotel biasanya menggunakan jaringan LAN (Local Area Network) .

Salah satu aplikasi jaringan LAN adalah penerapannya di salah satu hotel yang terletak di wilayah Jakarta Timur, sebenarnya hotel tersebut sudah terhubung dengan computer server yang berada dilantai 1 , namun dalam pelaksanaannya ada beberapa kendala dalam jaringan computer terutama pada computer client satu dengan client lainnya dalam sistem transmisi data di tiap lantai hotel. Permasalahan yang sering terjadi pada saat mengirim dan menerima e-mail antar sesama client computer sering terjadi keterlambatan pengiriman data, sehingga informasi yang didapat sangat lambat. Seperti diketahui bahwa kualitas suatu jaringan atau biasa dikenal dengan Quality Of Service (QoS) merupakan faktor terpenting untuk mendukung sarana dan prasarana komunikasi terutama dalam sistem transmisi data [1].

Dari permasalahan diatas maka perlu dilakukan monitoring dan analisa terhadap jaringan LAN, seperti delay, throughput dan Packet Loss, dengan tujuan agar dilakukan perbaikan guna peningkatan dan mengoptimalkan jaringannya secara efisien, apakah perlu adanya penambahan sirkuit atau komponen.

\section{METODOLOGI PENELITIAN}

Menganalisa satu satu hotel di wilayah Jakarta Timur yang sering bermasalah di aspek kualitas jaringan LAN pada tiap lantai, khususnya pada saat mengirim dan menerima email dan pada saat mengupload dan mendownload file, analisa menggunakan 3 parameter yaitu menghitung Delay, Throughput dan Packet Loss pada hari Senin-Minggu dari jam 8.00-17.00.

Analisa dilakukan mulai dari lantai 2-10, untuk lantai 1 adalah letak servernya, analisa dilakukan untuk mengetahui QoS dari suatu jaringan di tiap lantai, agar dapat dilakukan perbaikan jaringan atau penambahan bandwidth.

\subsection{Fungsi Jaringan Komputer}

Jaringan komputer adalah dua atau lebih komputer yang saling terhubung, bisa berbagi file, (data, Software) dan Peralatan (modem, Scanner, CDROM, dll) jaringan pada beberapa lokasi (email, link video conferences). Manfaat dari penggunaan jaringan komputer adalah :

\section{Sharing resources}

Bertujuan agar seluruh program atau peralatan lainnya dapat dimanfaatkan oleh orang yang ada pada jaringan komputer tanpa terpengaruh oleh lokasi maupun pengaruh dari pemakai [2]. 


\section{Media Komunikasi}

Jaringan komputer memungkinkan terjadinya komunikasi antar pengguna baik untuk teleconference maupun untuk mengirim pesan atau informasi yang penting lainnya.

3. Integrasi Data

Jaringan komputer dapat mencegah ketergantungan pada komputer pusat, karena setiap proses data tidak harus dilakukan pada satu komputer saja, melainkan dapat didistribusikan ketempat lainnya. Oleh karena itu, maka dapat terbentuk data yang terintegrasi yang memudahkan pemakai untuk memperoleh dan mengolah informasi setiap saat [3].

4. Pengembangan dan Pemeliharaan

Pengembangan peralatan dapat dilakukan dengan mudah dana menghemat biaya, karena setiap pembelian komponen seperti printer, maka tidak perlu membeli printer sejumlah komputer yang ada tetapi cukup satu buah saja. Karena printer itu dapat digunakan secara bersama-sama. Jaringan komputer juga memudahkan pemakai dalam merawat harddisk dan peralatan lainnya, misalnya untuk memberikan perlindungan terhadap serangan virus, maka pemakai cukup memusatkan perhatian pada harddisk yang ada pada komputer pusat.

5. Keamanan data sistem

Jaringan komputer dapat memberikan perlindungan terhadap data karena pemberian dan peraturan hak akses kepada setiap pengguna, serta teknik perlindungan terhadap harddisk sehingga data mendapatkan perlindungan yang efektif.
6. Sumber daya lebih efisien dan informasi terkini

Dengan pemakaian sumber daya secara bersama-sama, akan mendapatkan hasil yang maksimal dan kualitas yang tinggi. Selain itu data atau informasi yang diakses selalu terbaru, karena setiap perubahan yang terjadi dapat langsung diketahui oleh setiap pemakai.

\subsection{Jenis-jenis Jaringan Komputer}

Jenis jaringan komputer terbagi dua yaitu berdasarkan transmisi Jenis-jenis data dan berdasarkan jangkauan jaringan.

\subsubsection{Berdasarkan Transmisi Data}

Berdasarkan tipe transmisinya, jaringan dibagi menjadi dua bagian besar yaitu :

\section{1) Broadcast}

Sebuah metode pengiriman data, dimana data dikirimkan ke banyak titik sekaligus, tanpa melakukan pengecekan apakah titik tersebut siap atau tidak, atau tanpa memperhatikan apakah data itu sampai atau tidak [4].

Contoh : sebuah stasiun siaran melakukan siaran terus menerus tanpa mempedulikan apakah ada pesawat televisi ataupun radio yang memonitor siaran tersebut. Pengiriman data dengan tujuan semua alamat yang berada dalam 1 jaringan.

\section{2) Point to point}

Pada broadcast network, komunikasi data terjadi dalam sebuah saluran komunikasi, dimana data berupa paket yang dikirimkan dari sebuah komputer akan di sebarluaskan ke komputer lain yang ada dalam jaringan tersebut. Paket data ini akan di proses oleh komputer 
tujuan dan oleh komputer yang bukan tujuan makan paket data tersebut akan dibuang [5].

Sedangkan point to point network, komunikasi datanya terjadi melalui koneksi antar komputer, jadi sebuah paket data untuk mencapai tujuannya itu harus melewati beberapa komputer. Pemilihan rute yang baik akan mempengaruhi bagus atau tidaknya koneksi data dalam tipe jaringan tersebut.

\subsubsection{Berdasarkan Jangkauan Jaringan}

Berdasarkan jangkauan jaringan dibagi menjadi tiga bagian besar yaitu :

\section{1) LAN (Local Area Network)}

Local Area Network (LAN), merupakan jaringan milik pribadi didalam sebuah gedung atau kampus yang berukuruan sampai beberapa kilometer. LAN seringkali digunakan untuk menghubungkan Jaringan komputer adalah dua atau lebih komputer yang saling terhubung, bisa berbagi file, (data, Software) dan Peralatan (modem, Scanner, CDROM, dll) jaringan pada beberapa lokasi (email, link video conferences)[1].

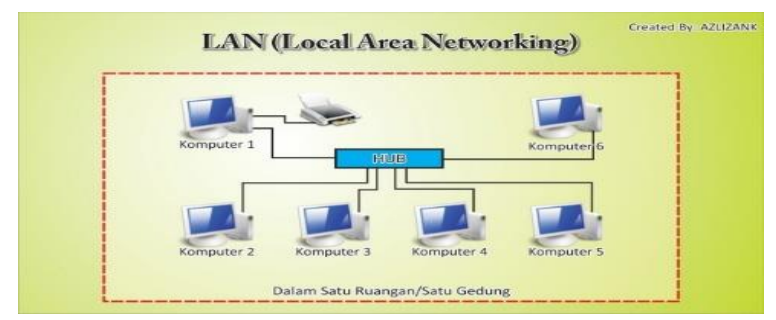

Gambar 1. Jaringan LAN

2) MAN (Metropolitan Area Network)

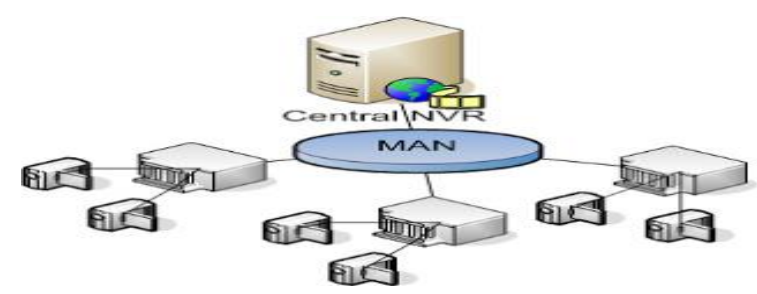

Gambar 2. Metropolitan Area Network
Metropolitan Area Network (MAN), pada dasarnya merupakan versi LAN yang berukuran besar dan biasanya menggunakan teknologi yang sama dengan LAN. MAN dapat mencakup kantor-kantor perusahaan yang letaknya berdekatan atau juga sebuah kota dan dapat dimanfaatkan untuk keperluan pribadi (swasta) atau umum, pada Gambar 2 di atas. MAN mampu menunjang data dan suara, bahkan dapat berhubungan dengan jaringan televisi kabel [6].

3) WAN (WIDE Area Network)

Wide Area Network (WAN), jangkauannya mencakup daerah geografis yang luas, sering kali mencakup sebuah negara bahkan benua. WAN terdiri dari kumpulan mesin-mesin yang bertujuan untuk menjalankan program-program (aplikasi) pemakai [7].

Sebagian besar WAN, jaringan terdiri dari sejumlah banyak kabel atau saluran telepon yang menghubungkan sepasang router. Bila dua router yang tidak mengandung kabel yang sama akan melakukan komunikasi, keduanya harus berkomunikasi secara tak langsung melalui router lainnya. ketika sebuah paket dikirimkan dari sebuah router ke router lainnya melalui router perantara atau lebih, maka paket akan diterima router dalam keadaan lengkap, disimpan sampai saluran output menjadi bebas, dan kemudian baru diteruskan.

Subnet yang mengandung prinsip seperti ini disebut subnet point-to-point, store-andforward, atau packet-switched, Terlihat pada Gambar 3. Hampir semua WAN (kecuali yang menggunakan satelit) memiliki subnet storeand-forward [8]. 


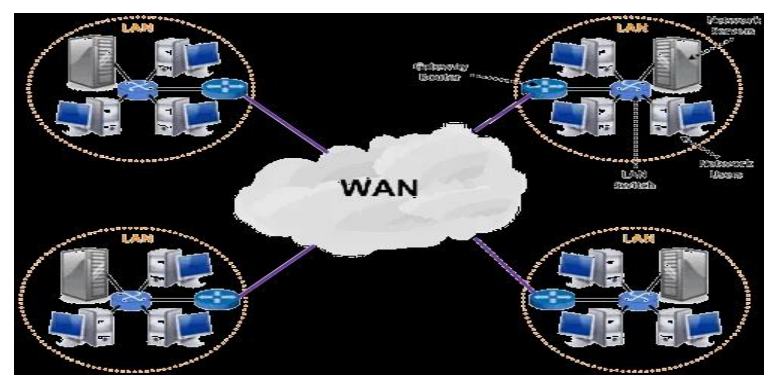

Gambar 3. Wide Area Network

\subsubsection{Berdasarkan Fungsi Jaringan.}

Berdasarkan tipe jaringannya, jaringan dibagi menjadi dua bagian besar yaitu :

1) Jaringan Client-Server

Jaringan yang terdiri dari client, yaitu mikrokomputer yang meminta data dan server, yaitu komputer yang menyuplai data.

\section{2) Peer to peer}

Pada jaringan ini, semua mikrokomputer dalam sebuah jaringan berkomunikasi secara langsung satu sama lain tanpa harus bersandar pada server. Komputer bisa berbagi file dan peripheral dengan seluruh komputer lainnya pada jaringan, jika semua komputer tersebut diberi hak akses [9].

\subsection{QoS (Quality Of Service)}

Quality of Service (QoS) atau Kualitas layanan adalah metode pengukuran yang digunakan untuk menentukan kemampuan sebuah jaringan seperti; aplikasi jaringan, host atau router dengan tujuan memberikan network service yang lebih baik dan terencana sehingga dapat memenuhi kebutuhan suatu layanan.

\section{Quality of Service (QoS) merupakan} sebuah arsitektur end-to-end dan bukan merupakan sebuah fitur yang dimiliki oleh jaringan. QoS suatu jaringan merujuk pada tingkat kecepatan dan kehandalan penyampaian berbagai jenis data di dalam suatu komunikasi.Melalui QoS seorang network administrator dapat memberikan prioritas trafik tertentu. QoS menawarkan kemampuan untuk mendefinisikan atribut-atribut layanan yang disediakan, baik secara kualitatif maupun kuantitatif [10].

Tujuan QoS menyediakan kualitas layanan yang berbeda-beda berdasarkan kebutuhan layanan di dalam jaringan pada Tabel 1.

Tabel 1. Indeks Parameter QOS

\begin{tabular}{lll}
\hline Nilai & Presentasi (\%) & Indeks \\
\hline $3,8-4$ & $95-100$ & $\begin{array}{l}\text { Sangat } \\
\text { Memuaskan }\end{array}$ \\
$3-3,79$ & $75-95,75$ & $\begin{array}{l}\text { Memuaskan } \\
2-2,99\end{array}$ \\
$50-74,75$ & $\begin{array}{l}\text { Kurang } \\
\text { Memuaskan }\end{array}$ \\
$1-1,99$ & $25-49,75$ & Buruk \\
\hline Sumber :TIPHON &
\end{tabular}

\subsection{Parameter QoS}

Menurut Sofana (2011), terdapat beberapa parameter Quality of Service (QoS), yaitu sebagai berikut [11]:

\section{Bandwidth}

Bandwidth adalah luas atau lebar cakupan frekuensi yang digunakan oleh sinyal dalam mediu1m transmisi. Bandwidth sering digunakan sebagai suatu sinonim untuk kecepatan transfer data (transfer rate) yaitu jumlah data yang dapat dibawa dari sebuah titik ke titik lain dalam jangka waktu tertentu (pada umumnya dalam detik).

\section{Throughput}

Throughput adalah kemampuan sebenarnya suatu jaringan dalam melakukan pengiriman data. Biasanya throughput selalu dikaitkan 
dengan bandwidth dalam kondisi yang sebenarnya. Bandwidth lebih bersifat fix sementara throughput sifatnya adalah dinamis tergantung trafik yang sedang terjadi baik pada saat pengirim maupun menerima.

Beberapa faktor yang mempengaruhi bandwidth dan throughput yaitu antara lain piranti jaringan, tipe data yang ditransfer, banyaknya pengguna jaringan, topologi jaringan, spesifikasi computer client/user, spesifikasi server komputer, induksi listrik, cuaca [12].

Throughput adalah kecepatan (rate) transfer data efektif yang diukur dalam bps. Throughput merupakan jumlah total kedatangan paket yang sukses yang diamati pada destination selama interval waktu tertentu dibagi oleh durasi interval waktu tersebut. Throughput dirumuskan pada rumus (1):

Throughput $=\frac{\text { Jumlah data Yang diterima }}{\text { Waktu Pengiriman data }}$

Adapun standar Throughput menurut TIPHON adalah pada Tabel 2 :

Tabel 2. Tabel Troughput

\begin{tabular}{llc}
\hline $\begin{array}{l}\text { Katagori } \\
\text { Troughput }\end{array}$ & Troughput & Indeks \\
\hline Sangat Jelek & $0-338 \mathrm{kbps}$ & 0 \\
Jelek & $338-700 \mathrm{kbps}$ & 1 \\
Sedang & $700-1200 \mathrm{kbps}$ & 2 \\
Bagus & $1200 \mathrm{kbps}-2,1 \mathrm{Mbps}$ & 3 \\
Sangat Bagus & $>2,1 \mathrm{Mbps}$ & 4 \\
\hline Sumber $:$ TIPHON &
\end{tabular}

\section{Packet Loss}

$\begin{array}{cccc}\text { Packet loss adalah } & \text { parameter } & \text { yang } \\ \text { menggambarkan } & \text { suatu } & \text { kondisi } & \text { yang }\end{array}$
menunjukkan jumlah total paket yang hilang. Paket yang hilang ini dapat terjadi karena collision dan congestion pada jaringan [13]. Packet Loss merupakan kegagalan transmisi paket data mencapai tujuannya yang disebabkan oleh beberapa kemungkinkan, antara lain yaitu:

a. Terjadinya overload trafik didalam jaringan.

b. Tabrakan (congestion) dalam jaringan.

c. Error yang terjadi pada media fisik.

d. Kegagalan yang terjadi pada sisi penerima antara lain bisa disebabkan karena Overflow yang terjadi pada buffer.

Packet loss dapat terjadi karena kesalahan yang diperkenalkan oleh medium transmisi fisik. Hal hal yang mempengaruhi terjadinya packet loss juga bisa karena kondisi geografis seperti kabut, hujan, gangguan radio frequensi, sel handoff selama roaming, dan interferensi seperti pohon-pohon, bangunan, dan pegunungan. Packet Loss dihitung berdasarkan persentase paket yang berhasil dikirim, dirumuskan pada persamaan (2):

Packetloss $=\frac{\text { Paket data dikirim-Paket Data di Terima }}{\text { Paket Data Di Kirim }} \times 100 \%$

Adapun standar Packet Loss Menurut TIPHON terlampir di Tabel 3 :

Tabel 3. Tabel Packet Loss

\begin{tabular}{lcc}
\hline $\begin{array}{l}\text { Katagori Packet } \\
\text { Loss }\end{array}$ & Packet Loss & Indeks \\
\hline Jelek & $>25 \%$ & 1 \\
Sedang & $14-24 \%$ & 2 \\
Bagus & $3-14 \%$ & 3 \\
Sangat Bagus & $0-2 \%$ & 4 \\
\hline
\end{tabular}

Sumber :TIPHON

\section{Latency (Delay)}

Latency/Delay adalah total waktu tunda suatu paket yang diakibatkan oleh proses transmisi dari satu titik ke titik lainnya yang menjadi tujuan, Delay di dalam jaringan terdiri dari delay processing, delay packetization, delay serialization, delay jitter buffer dan delay 
network [2], dengan persamaan rumus (3) dibawah:

Delay $=$ Waktu paket Sampai - Waktu Paket dikirim

Adapun standar Latency/delay menurut TIPHON pada Tabel 4.

Tabel 4. Tabel Delay

\begin{tabular}{llc}
\hline Katagori Delay & Delay & Indeks \\
\hline Jelek & $>450 \mathrm{~s}$ & 1 \\
Sedang & $300-450 \mathrm{~s}$ & 2 \\
Bagus & $150-300 \mathrm{~s}$ & 3 \\
Sangat Bagus & $<150 \mathrm{~s}$ & 4 \\
\hline
\end{tabular}

Sumber :TIPHON

\section{HASIL DAN PEMBAHASAN}

Pada bagian ini menjelaskan secara detail analisa Delay, Throughput dan Packet Loss, berdasarkan analisa metode TIPHON.

\subsection{Blok Diagram Analisa}

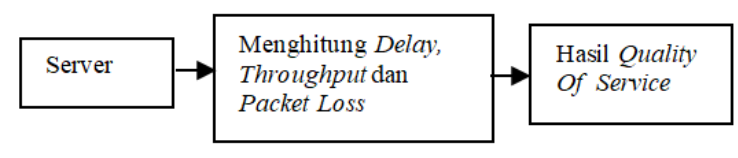

\section{Gambar 4. Blok Diagram Analisa}

Gambar 4 menjelaskan cara kerja blok diagram diatas adalah server yang berada di lantai 1 pada hotel tersebut, akan dianalisa outputnya di setiap lantainya pada saat mengirim email, menerima email, saat mendownload dan menupload data baik data, gambar dan voice, untuk keperluan menghitung besarnya Delay, Throughput dan Packet Loss, setelah data semua didapat akan dihitung rata-rata agar didapatkan hasil yang maksimal, setelah dirata-ratakan akan diperoleh katagori ditiap lantai tersebut, sehingga didapat QoS nya.

\subsection{Analisa QoS}

Analisa QoS dilakukan 3 parameter di tiap lantai Hotel tersebut pada jam sibuk di hari Senin - Minggu, saat mengirim dan menerima data email serta pada saat melakukan upload dan download file.

\section{1) Delay}

Pengujian Delay dilakukan di tiap lantai pada jam sibuk yaitu hari Senin sampai Minggu jam 08.00 - 17.00 WIB, pengujian dilakukan pada salah satu computer client di tiap lantai untuk melihat tingkat delay selama pengiriman dan menerima data seperti email, di Tabel 5.

Tabel 5. Pengujian Delay Tiap lantai saat mengirim dan menerima $E$-mail

\begin{tabular}{|c|c|c|c|c|c|}
\hline $\begin{array}{c}\text { Uji } \\
\text { Tiap } \\
\text { Lantai }\end{array}$ & $\begin{array}{c}\text { Paket } \\
\text { Sampai } \\
(s)\end{array}$ & $\begin{array}{c}\text { Paket } \\
\text { dikirim } \\
(s)\end{array}$ & $\begin{array}{c}\text { Delay } \\
(s)\end{array}$ & $\begin{array}{c}\text { In- } \\
\text { deks }\end{array}$ & $\begin{array}{c}\text { Kata- } \\
\text { gori }\end{array}$ \\
\hline 2 & 412 & 211 & 201 & 3 & Bagus \\
\hline 3 & 316 & 240 & 76 & 4 & $\begin{array}{c}\text { Sangat } \\
\text { Bagus }\end{array}$ \\
\hline 4 & 443 & 224 & 219 & 3 & Bagus \\
\hline 5 & 411 & 243 & 168 & 3 & Bagus \\
\hline 6 & 316 & 276 & 49 & 4 & $\begin{array}{c}\text { Sangat } \\
\text { Bagus }\end{array}$ \\
\hline 7 & 445 & 229 & 216 & 3 & Bagus \\
\hline 8 & 412 & 214 & 198 & 3 & Bagus \\
\hline 9 & 400 & 224 & 176 & 3 & Bagus \\
\hline 10 & 403 & 240 & 163 & 3 & Bagus \\
\hline Rata2 & 395.33 & 233.44 & 161.88 & 3.22 & Bagus \\
\hline
\end{tabular}

Pengujian dilakukan saat computer client di tiap lantai melakukan upload dan download file di hari dan jam sibuk, terlihat di Tabel 6.

Tabel 6. Pengujian Delay Tiap lantai saat Upload dan Download file

\begin{tabular}{cccccc}
\hline $\begin{array}{c}\text { Uji } \\
\text { Tiap } \\
\text { Lantai }\end{array}$ & $\begin{array}{c}\text { Paket } \\
\text { Sampai } \\
(\boldsymbol{s})\end{array}$ & $\begin{array}{c}\text { Paket } \\
\text { dikirim } \\
(\boldsymbol{s})\end{array}$ & $\begin{array}{c}\text { Delay } \\
(\boldsymbol{s})\end{array}$ & $\begin{array}{c}\text { In- } \\
\text { deks }\end{array}$ & $\begin{array}{c}\text { Kata- } \\
\text { gori }\end{array}$ \\
\hline 2 & 444 & 233 & 211 & 3 & Bagus \\
3 & 499 & 215 & 284 & 3 & Bagus \\
4 & 399 & 199 & 200 & 3 & Bagus \\
5 & 451 & 297 & 154 & 4 & Sangat \\
& & & & & Bagus \\
6 & 400 & 210 & 190 & 3 & Bagus \\
7 & 399 & 256 & 143 & 4 & Sangat \\
& & & & & Bagus \\
8 & 401 & 222 & 179 & 3 & Bagus \\
9 & 411 & 245 & 166 & 3 & Bagus \\
10 & 377 & 211 & 166 & 3 & Bagus \\
Rata2 & 420.11 & 232 & 188.11 & 3.22 & Bagus \\
\hline
\end{tabular}




\section{2) Throughput}

Pengujian Throughput dilakukan di tiap lantai pada jam sibuk yaitu hari Senin sampai Minggu jam 08.00 - 17.00 WIB, pengujian dilakukan pada salah satu computer client di tiap lantai untuk melihat tingkat Throughput selama pengiriman dan menerima data seperti email di Tabel 7.

Tabel 7. Pengujian Throughput Tiap lantai saat mengirim dan menerimaE-mail

\begin{tabular}{lccccc}
\hline $\begin{array}{c}\text { Uji } \\
\text { Tiap } \\
\text { Lantai }\end{array}$ & $\begin{array}{c}\text { Jumlah } \\
\text { data } \\
\text { yang } \\
\text { diterima } \\
(\boldsymbol{k b})\end{array}$ & $\begin{array}{c}\text { Waktu } \\
\text { pengiri } \\
\text { man } \\
\text { data }(\boldsymbol{s})\end{array}$ & $\begin{array}{c}\text { Through } \\
\text { t-put }\end{array}$ & $\begin{array}{c}\text { In- } \\
\text { deks }\end{array}$ & $\begin{array}{c}\text { Kata- } \\
\text { gori }\end{array}$ \\
\hline 2 & 401300 & 301 & 1333.22 & 3 & Bagus \\
3 & 399022 & 300 & 1330.07 & 3 & Bagus \\
4 & 400102 & 298 & 1342.62 & 3 & Bagus \\
5 & 332040 & 276 & 1203.04 & 3 & Bagus \\
6 & 391912 & 381 & 1028.64 & 2 & Sedang \\
7 & 301371 & 314 & 959.78 & 2 & Sedang \\
8 & 401283 & 263 & 1525.79 & 3 & Bagus \\
9 & 206721 & 250 & 826.88 & 2 & Sedang \\
10 & 300123 & 301 & 997.08 & 2 & Sedang \\
Rata2 & 348208.2 & 301.22 & 1171.9 & 2.55 & Sedang \\
\hline
\end{tabular}

Pengujian dilakukan saat computer client di tiap lantai melakukan upload dan download file di hari dan jam sibuk, terlampir di table 8 .

Tabel 8. Pengujian Throughput Tiap lantai saat Upload dan Download file

\begin{tabular}{lccccc}
\hline $\begin{array}{c}\text { Uji } \\
\text { Tiap } \\
\text { Lantai }\end{array}$ & $\begin{array}{c}\text { Jumlah } \\
\text { data yang } \\
\text { diterima } \\
(\boldsymbol{k b})\end{array}$ & $\begin{array}{c}\text { Waktu } \\
\text { pengiri } \\
\text { man } \\
\text { data } \\
(\boldsymbol{s})\end{array}$ & $\begin{array}{c}\text { Throught } \\
-\boldsymbol{p u t}\end{array}$ & $\begin{array}{c}\text { In- } \\
\text { deks }\end{array}$ & $\begin{array}{c}\text { Kata- } \\
\text { gori }\end{array}$ \\
\hline 2 & 400111 & 326 & 1227.33 & 3 & Bagus \\
3 & 402892 & 335 & 1202.66 & 3 & Bagus \\
4 & 399281 & 297 & 1344.38 & 3 & Bagus \\
5 & 347932 & 294 & 1183.44 & 2 & Sedang \\
6 & 410000 & 304 & 1348.68 & 3 & Bagus \\
7 & 289578 & 411 & 704.57 & 2 & Sedang \\
8 & 398722 & 401 & 994.32 & 2 & Sedang \\
9 & 458111 & 396 & 1156.85 & 2 & Sedang \\
10 & 300133 & 291 & 1031.39 & 2 & Sedang \\
Rata2 & 378528.88 & 339.44 & 1029.3 & 2.44 & Sedang \\
\hline
\end{tabular}

\section{3) Packet Loss}

Pengujian Packet Loss dilakukan di tiap lantai pada jam sibuk yaitu hari Senin sampai Minggu jam 08.00 - 17,00 WIB, pengujian dilakukan pada salah satu computer client di tiap lantai untuk melihat tingkat Packet Loss selama pengiriman dan menerima data seperti email di Tabel 9.

Tabel 9. Pengujian Packet Loss Tiap lantai saat E-mail

\begin{tabular}{cccccc}
\hline $\begin{array}{c}\text { Uji } \\
\text { Tiap } \\
\text { Lantai }\end{array}$ & $\begin{array}{c}\text { Paket } \\
\text { dikirim }\end{array}$ & $\begin{array}{c}\text { Paket } \\
\text { di } \\
\text { terima }\end{array}$ & $\begin{array}{c}\text { Packet } \\
\text { Loss }(\%)\end{array}$ & $\begin{array}{c}\text { In- } \\
\text { deks }\end{array}$ & $\begin{array}{c}\text { Kata- } \\
\text { gori }\end{array}$ \\
\hline 2 & 234 & 222 & 5 & 3 & Bagus \\
3 & 341 & 322 & 6 & 3 & Bagus \\
4 & 265 & 241 & 9 & 3 & Bagus \\
5 & 299 & 277 & 7 & 3 & Bagus \\
6 & 311 & 299 & 4 & 3 & Bagus \\
7 & 291 & 278 & 4 & 3 & Bagus \\
8 & 321 & 300 & 7 & 3 & Bagus \\
9 & 334 & 305 & 9 & 3 & Bagus \\
10 & 290 & 267 & 8 & 3 & Bagus \\
Rata2 & 298.44 & 279 & 6.55 & 3 & Bagus \\
\hline
\end{tabular}

Pengujian dilakukan saat computer client di tiap lantai melakukan upload dan download file di hari dan jam sibuk, pada Tabel 10.

Tabel 10. Pengujian Packet Loss Tiap lantai saat Upload dan Download file

\begin{tabular}{cccccc}
\hline $\begin{array}{c}\text { Uji } \\
\text { Tiap } \\
\text { Lantai }\end{array}$ & $\begin{array}{c}\text { Paket } \\
\text { Dikirim }\end{array}$ & $\begin{array}{c}\text { Paket } \\
\text { diterima }\end{array}$ & $\begin{array}{c}\text { Packet } \\
\text { loss } \\
(\%)\end{array}$ & $\begin{array}{c}\text { In- } \\
\text { deks }\end{array}$ & $\begin{array}{c}\text { Kata- } \\
\text { gori }\end{array}$ \\
\hline 2 & 243 & 232 & 5 & 3 & Bagus \\
3 & 254 & 244 & 4 & 3 & Bagus \\
4 & 266 & 254 & 5 & 3 & Bagus \\
5 & 298 & 277 & 7 & 3 & Bagus \\
6 & 311 & 299 & 4 & 3 & Bagus \\
7 & 302 & 289 & 4 & 3 & Bagus \\
8 & 268 & 256 & 4 & 3 & Bagus \\
9 & 298 & 276 & 7 & 3 & Bagus \\
10 & 292 & 277 & 5 & 3 & Bagus \\
Rata2 & 281.33 & 267.11 & 5 & 3 & Bagus \\
\hline
\end{tabular}

\section{4) Pembahasan QoS}

Pada pembahasan QoS dilakukan penggabungan antara 3 parameter untuk mendapatkan hasil keseluruhan agar dapat diambil kesimpulan. Delay, Packet Loss dan Throughput pada tabel 11 adalah nilai rata-rata dari tabel pengujian saat mengirim dan menerima email serta tabel upload dan download file. Terlihat semua elemen memiliki katagori Bagus dan hasil yang terakhir adalah 
memuaskan, maka bagian maintenance harus memperhatikan lebih detail lagi jaringan pada hotel tersebut di tiap lantainya, seperti di Tabel 11.

\section{Tabel 11. Nilai Parameter pada hari Senin - Minggu}

\begin{tabular}{cccc}
\hline Parameter & $\begin{array}{c}\text { Nilai Rata- } \\
\text { rata }\end{array}$ & $\begin{array}{c}\text { In- } \\
\text { deks }\end{array}$ & Kategori \\
\hline Delay & $174.99 \mathrm{~s}$ & 3 & Bagus \\
Throughput & $1200.6 \mathrm{kbps}$ & 3 & Bagus \\
Packet Loss & $5.78 \%$ & 3 & Bagus \\
Rata-rata & & 3 & Memuaskan \\
\hline
\end{tabular}

\section{KESIMPULAN}

Delay didapat nilai rata-rata sebesar 174.99 s pada hari Senin - Minggu, maka dapat dikatakan katagori Bagus. Throughput didapat nilai rata-rata sebesar $1200.6 \mathrm{kbps}$ pada hari Senin - Minggu, maka dapat dikatakan katagori Bagus. Packet Loss didapat nilai rata-rata sebesar $5.78 \%$ pada hari Senin - Minggu, maka dapat dikatakan katagori Bagus. Maka di dapat hasil QoS pada hari Senin - Minggu didapat indeks sebesar 3 dikatagorikan Memuaskan, tetapi tetap bagian maintenance harus sering mengecek kualitas jaringan.

\section{DAFTAR PUSTAKA}

[1] R. Rasmila and T. G. Laksana, "The Implementation of Top Down Approach Method on Redesign of LAN Harvani Hotel Palembang," JURNAL INFOTEL, vol. 11, no. 1, p. 15, Mar. 2019, doi: 10.20895/infotel.v11i1.410.

[2] K. J. Komputer, T. Informasi, and D. Elektro, "Analisis Quality of Service (QoS) Jaringan Internet Pada Website eLearning Universitas Syiah Kuala Berbasis Wireshark," 2021.
[3] R. S. Dewi, Analisis Dampak Integrasi Data Terhadap Kecepatan Pelayanan Publik Di Kota Surabaya,"2018.

[4] M. Yusril and H. Setyawan, Simulasi Paket-Paket Broadcast Dan Implementasi Subnetting, 2017.

[5] A. Wibowo and Ristyo, Perancangan Dan Implementasi Jaringan Wireless Point To Point Untuk Warga Desa Trimodadi Kec Abung Selatan, 2020.

[6] Desmira and P. Pangestu, "Analisis Optimalisasi Kinerja Jaringan MAN pada Layanan Internet Berbasis Mikrotik di PT. Bina Technindo Solution," Prosisko, pp. 8-17, 2021.

[7] Rengel Julian and Alek Wijaya, "Analisa dan pengembangan Jaringan WAN Pada Gedung Bagian Lalin Di Dishub Pemprov Sumsel," Seminar Hasil Penelitian Vokasi (SEMHAVOK), pp. 34-40, 2017.

[8] S. Hidayatulloh and W. Wahyudin, "Perancangan Wide Area Network (WAN) Dengan Teknologi Virtual Private Network (VPN)," Jurnal Teknik Komputer AMIK BSI, pp. 7-14, 2019, doi: 10.31294/jtk.v4i2.

[9] J. Komputer, "Fakultas Komputer Indah Kusuma Astuti Section 01."

[10] B. Sugiantoro and Y. B. Mahardhika, "Analisis Quality Of Service Jaringan Wireless Sukanet Wifi Di Fakultas Sains Dan Teknologi Uin Sunan Kalijaga," Jurnal Teknik Informatika, vol. 10, no. 2, pp. 191-201, Jan. 2017, doi: 10.15408/jti.v10i2.7027.

[11] S. Wisnu Pamungkas, Kusrini, and E. Pramono, Analisis Quality of Service (QoS) Pada Jaringan Hotspot SMA Negeri XYZ, 2018.

[12] M. Rusdan, Pengujian Jaringan Nirkabel Stt Bandung Menggunakan Quality Of Service (Qos), 2019.

[13] M. Rusdan, T. Informatika, S. Tinggi, T. Bandung, and K. Kunci, Pengujian Jaringan Nirkabel Stt Bandung Menggunakan Quality Of Service (QOS), 2019. 